\title{
Participle agreement and clitic omission
}

Vicenç Torrens

Facultad de Psicología, National University of Distance Learning, Spain

https://doi.org/10.36505/ExLing-2011/04/0034/000203

\begin{abstract}
Object clitic omission has been considered to be a general feature of child grammar. In this paper we show that while omission is high in young Catalan-speaking children, it is very low in Spanish-speaking children. This difference can be attributed to the availability of participle agreement when objects cliticise. I present a research where we test, through a grammaticality judgement task, the sensitivity of Catalan and Spanish children to participle agreement and find a statistically significant difference between the two languages.
\end{abstract}

Key words: clitics, omission, participle agreement.

\section{Theoretical Background}

In the literature of language development, some analyses have been put forward to account for the phenomenon known as object clitic omission (see e.g. Guasti, 1993/1994, Hamann, Rizzi and Frauenfelder, 1996; Avram 2000, Schaeffer 2000, Jakubowicz et al. 1997). In this paper we challenge the idea that clitic omission is a universal feature of all child grammars, and show that it holds of only a subset. While object clitic omission is found in languages such as French and Italian, we demonstrate that it is found to a significantly lesser extent in other languages, such as Spanish, and we argue that there is a correlation between object clitic omission and participle agreement. This correlation can be accounted for under Wexler's (1998) Unique Checking Constraint.

The hypothesis we entertain is that in child grammar object clitic omission results from the interaction of the properties of some grammars with a maturational principle, the Unique Checking Constraint (UCC) (Wexler 1998). There is nothing that singles out clitics and their acquisition; rather, there is a more general constraint in the child's grammar, the UCC, which grants, for some languages, optional clitic omission, together with other features of child grammar, the most well-known of which is the optional infinitive stage. The Unique Checking Constraint, which acts in conjunction with Minimise Violations, is formulated as follows:

Unique Checking Constraint: the D-feature of DP can only check against one functional feature.

Minimise Violations: Given an LF, choose a numeration the derivation of which violates as few grammatical properties as possible. If two numerations are both minimal violators, either one may be chosen.

ExLing 2011: Proceedings of 4th Tutorial and Research Workshop on Experimental Linguistics, 25-27 May, Paris, France 
The UCC limits the derivations that are possible for the child to compute; if the target language of the child requires a derivation with double checking of uninterpretable features by a certain grammatical constituent, the child grammar will render that derivation a violation of the UCC. However, should that derivation compete with another derivation also involving a grammaticality violation, both derivations would be, by Minimise Violations, equally bad for the child's grammar, and would thus be expected to occur optionally.

Since the different omission rate between Catalan and Spanish is attributed to the existence/lack of participle agreement in these languages, the assumption is made that participle agreement is a feature of grammar from early on. Agreement has been found to be an early acquisition in other domains such as subject-verb agreement. However, the only direct evidence we have so far for the presence of participle agreement in child grammar comes from the production of participle agreement, which is not found for all children (nor for all adults) in standard Catalan. Since we claim that the mechanisms underlying participle agreement are the same for all children, whether participle agreement is overt or not, it is relevant to give independent evidence of the existence of participle agreement in child Catalan.

\section{Experiment}

\section{Procedure}

In order to test the availability of participle agreement in Catalan and Spanish, we ran a grammaticality judgement task. We tested 40 Catalanspeaking children $(2 ; 2,12-6 ; 0,25)$ and 40 Spanish-speaking children $(2 ; 5,13$ $4 ; 10,8)$ and 10 control adults from the same areas where the first experiment was carried out.

The task was designed to see whether participle agreement could be a constitutive feature of child Catalan grammar despite its optionality, and how it differed from Spanish. The experimental items included sentences with participle agreement, sentences without participle agreement and, only for Catalan, sentences with unmatched participle agreement. The grammaticality judgement task consisted of nine sentences for Catalan and eight sentences for Spanish. A grammaticality judgement task with subjectverb agreement mismatches was introduced as control, and children who could not detect them at all were excluded as unable to perform a grammaticality judgement task.

Children were first introduced to the task by means of ill formed word order sequences. Then, after they had been familiarized with these examples, control and experimental items were presented to them in pseudorandom order. The experimenter showed the child short stories consisting of two 
Participle agreement and clitic omission 141

pictures portraying an event; the story was described by two sentences, the first of which provided the antecedent for the clitic in the second. The second sentence was pronounced clearly and the child was asked to judge whether it was a good sentence for him/her or not.

\section{Results}

For children, the rates of acceptance appear in Tables 1 and 2 (where A agreement, $\mathrm{N}$ no agreement, SA subject-verb agreement). The adult controls provided the expected responses; in Spanish A and ungrammatical SA were rejected and only $\mathrm{N}$ was accepted in all cases.

Table 1 Rates of acceptance in Catalan.

\begin{tabular}{|l|c|c|c|}
\hline \hline & $\mathrm{A}$ & $\mathrm{N}$ & $* \mathrm{SA}$ \\
\hline 2-year-olds i & $9 / 9$ & $9 / 9$ & $0 / 3$ \\
\hline 3-year-olds & $27 / 27$ & $27 / 27$ & $3 / 18$ \\
\hline 4-year-olds & $24 / 30$ & $28 / 30$ & $0 / 20$ \\
\hline
\end{tabular}

Table 2. Rates of acceptance in Spanish.

\begin{tabular}{|l|c|c|c|}
\hline \hline & $* \mathrm{~A}$ & $\mathrm{~N}$ & $* \mathrm{SA}$ \\
\hline 2-year-olds i & $8 / 15$ & $14 / 15$ & $0 / 10$ \\
\hline 3-year-olds & $2 / 30$ & $30 / 30$ & $0 / 20$ \\
\hline 4-year-olds & $0 / 30$ & $30 / 30$ & $0 / 20$ \\
\hline \hline
\end{tabular}

The results indicate that adult-like performance is achieved at three for Spanish and at five for Catalan. If we look at the acceptance rate of matched participle agreement, Catalan-speaking children are target-like at age three also. The two languages display very different patterns: while in Spanish there is early rejection of participle agreement and this develops steadily, in Catalan there is overacceptance of mismatched agreement (differences statistically significant between Catalan and Spanish for the agreement condition, for all ages $(\mathrm{P}<0.001))$. This result witnesses the child's sensitivity to participle agreement, and also gives empirical ground to a formerly unverified assumption: the availability of participle agreement in child grammar from early records - critical for the Wexler et al. analysis of clitic omission to hold.

\section{Conclusion}

The results of our elicitation experiment allows us to conclude that object clitic omission is a feature of the early stage of grammatical development, which is nevertheless not found universally. This crosslinguistic variation can be accounted for under a maturational principle, the UCC, which sets limits on the checking operations in a derivation. Some languages' object 
clitics - e.g. those of Spanish - do not require the application of doublechecking operations and are therefore adult-like from the earliest productions. Some other object clitics - e.g. those of Catalan - require double checking operations due to an additional participle agreement operation. There is one further consequence of our study regarding the optional character of participle agreement in the variety of Catalan tested, when compared to Italian: the optionality of participle agreement appears to be inconsequential. In the grammaticality judgement task, we provide independent evidence that child grammar is sensitive to the participle agreement feature in the target language, given that the results for Catalan sharply contrast with those for Spanish.

\section{References}

Avram, L. 2000. Clitic Omission in Child Romanian. Psycholinguistic Colloquium. University of Potsdam.

Guasti, M.T. 1993/1994. Verb syntax in Italian child grammar: finite and non-finite verbs. Language Acquisition 3, 1-40.. Place, Publisher.

Hamann, C., Rizzi, L., Frauenfelder, U. 1996. On the Acquisition of the Pronoun System in French. In Clahsen, H. (ed.), Generative Perspectives on Language Acquisition. Amsterdam, John Benjamins.

Jackubowicz, C. 1997, Müller, N., Biemer, B., Rigaut, C 1997. The Case of Subject and Object Omission in French and German. In Hughes, E., Hughes, M, Greenhill, A. (eds.), Boston University Conference on Language Development Proceedings, 21, Somerville, MA, Cascadilla Press.

Schaeffer, J. 2000. The Acquisition of Direct Object Scrambling and Clitic Placement. Amsterdam, John Benjamins.

Wexler, K. 1998. Very early parameter setting and the unique checking constraint: A new explanation of the optional infinitive stage. Lingua 106, 23-79. 